\title{
土砂の掃流状集合流動について
}

Sediment Gravity Flow on Relatively Gentle Slopes

九州大学工学部 正 員 橋 本 晴 行
長崎大学工学部 正 員 椿 東一郎
九州大学工学部 正 員 平 野 宗夫

1. はじめに

急勾配で発生・流下した土石流が緩勾配の溪流出口に達し、堆積する亡、後続流は堆積土砂の上を流れ、 粒子浱度の薄い水流層と高濃度層の上・下 2 層に分蜼したような流れを呈する。この流れは、高濃度層では 粒子同士の頻繁な接触によって粒子間応力が発生し、土石流のような挙動を示すが、一方上部の水流層では 掃流砂に類似した様相も示す。このような掃流仯と土石流の中間的な土仯輸送形態は掃流状集合流動と呼ば れ、土石流の堆積問題に関連するとともに土石流から掃流砂への遷移現象として重要な問題となっている。 これについては従来より若干の研究が行われているが、その特性は十分に明らかにされてはいない。

本研究では、現象として単純砂磪粒子の掃流状集合流動を対象とし、まずその流動特珄について詳細な 実験を行った。ついで、粒子間応力が卓越する高濃度層の上に一様な流速分布の水流層が存在する 2 層流モ デルを提示し，その特性について理論的な検討を加えている。

\section{2. 実験の方法}

表-1 河床材料の特性之実験条件

長さ $6.7 \mathrm{~m}$, 幅 $20 \mathrm{~cm}$ 可変勾配水 路に表一 1 に示すような均一な砂碑を 厚さ $10 \mathrm{~cm}$ に敷き，あらかじめ浸透水

\begin{tabular}{|c|c|c|c|c|c|c|}
\hline Case & $d(\mathrm{~mm})$ & $\sigma\left(\mathrm{g} / \mathrm{cm}^{3}\right)$ & $C_{*}$ & $q_{\text {wo }}\left(\mathrm{cm}^{2} / \mathrm{s}\right)$ & $\theta_{11}$ (degree) & $h / d$ \\
\hline$S I$ & 4.6 & 2.59 & 0.58 & 200 & $2 \sim 14$ & $6 \sim 10$ \\
\hline$S I I$ & 4.4 & 2.59 & 0.60 & 660 & $2 \sim 14$ & $10 \sim 16$ \\
\hline
\end{tabular}
で堆積層を飽和させた後, 上流端から給水を行い，流れを発生させた。

発生した流れにトレーサーを流し，水路の真上および側方からVTRカメラや $16 \mathrm{~mm}$ 高速度カメラ (10 0 コマ/S）でそれを撮影した。表面流速の測定ではトレーサーとして発泡スチロールを，水流の流速分布 の测定では比重が約 1 の中立粒子（積水化成品工業製のピオセラン粒子）をそれぞれ用いた。

水位と河床は $16 \mathrm{~mm}$ フィルから読み取って求めた。また, 下流端では流れを先端から断続的に採取し, 全流量や輸送濃度を求めた。このとき，採取時間を正確に測定するため，採取する状態をVTRで撮影した。 3. 実験の結果

（1）流れの構造と流速分布

撮影された $16 \mathrm{~mm}$ フィルムから流れを観察すると，流れの上部は砂磉眼度 が薄く、追跡可能な粒子は少ないのに対して、下部は比較的粒子濃度が濃く 追跡も容易である（図一1）。これらの粒子を追跡してみると，水路㑯斜角 $\theta_{0}=2^{\circ} \sim 4^{\circ}$ では, 粒子は河床之相互作用を及ほしあいながら移動し掃流 砂とみなされるのに対して， $\theta_{0}>8^{\circ}$ では移動粒子間で相互作用を及ぼし土 石流の上うな挙動を示している。

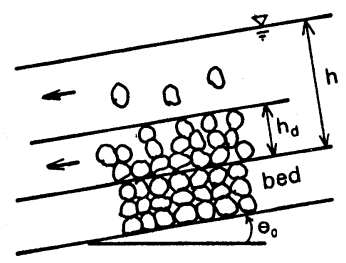

図一 1 流れの模式図

このような流れに中立粒子を投入すると，大部分は高濃度の砂䂿粒子層に妨げられて上部にとどまり，水

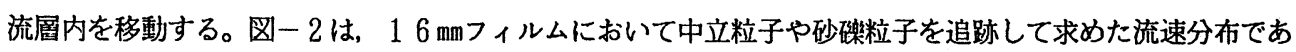
る。ここに, クは水梁で無次元化した高さである。水流層ではバラッキが大きいものの，ほほ一様な分布を 
示すのに対して, 高濃度層ではせん断流的で顕著 な速度勾配を示す。このようなせん断層の厚さ $h_{d}$ を読み取り, 水深で無次元化した結果を図一 3に示す。勾配の增加につれ，全体的に一様な流 速分布からせん断流的な分布へ変化していき， $\theta_{0}=14^{\circ}$ で土石流のそれに接続することが分る。

(2) 濃度之抵抗則
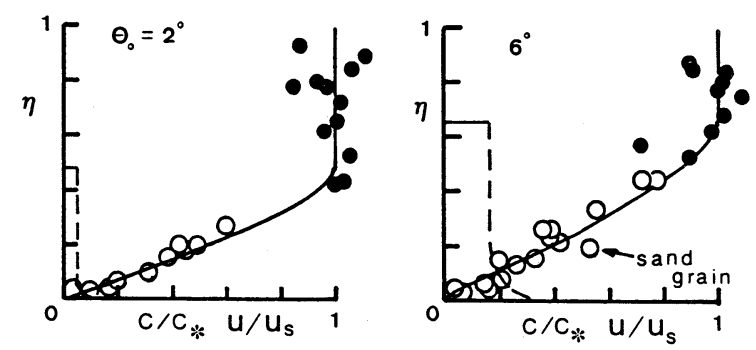

図一 4 は単位幅当りの全流量 $q_{t}$, 輸送濃度

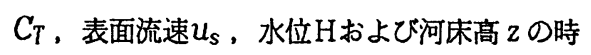
間的変化を示したものである。この実験では, $q_{t} \gg C_{T}$ は $t \leftrightharpoons 10$ 秒 18秒の間でほほ定常 になっている。しかしデータ解析に当っては,こ の時間のなかでも河床侵食の影響が少ない先端に 近いデータ（罒中の斜線）を用いることにした。

掃流状集合流動では水面流動が激しいのも一つ
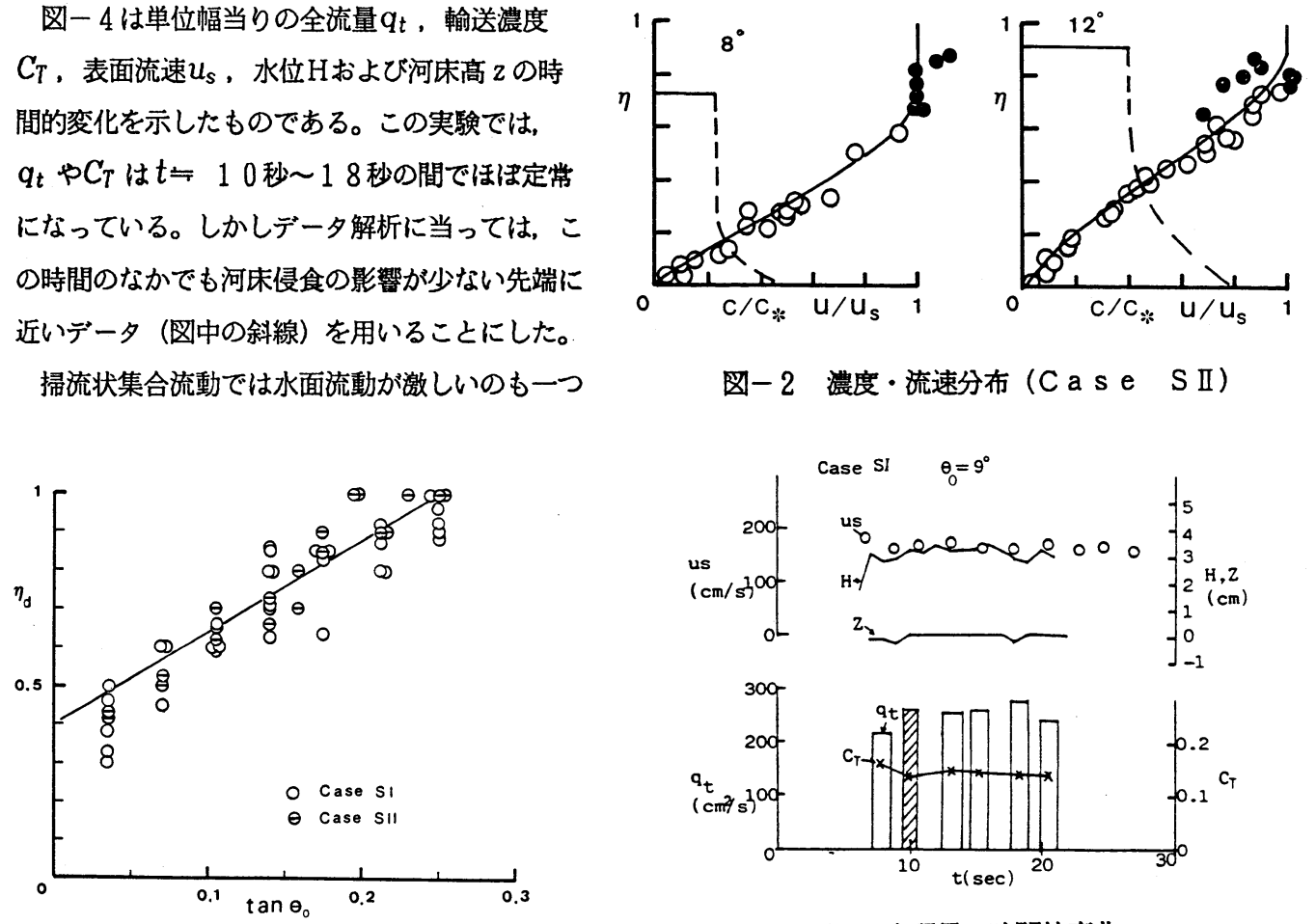

図-2 濃度・流速分布（C a s e S I ）

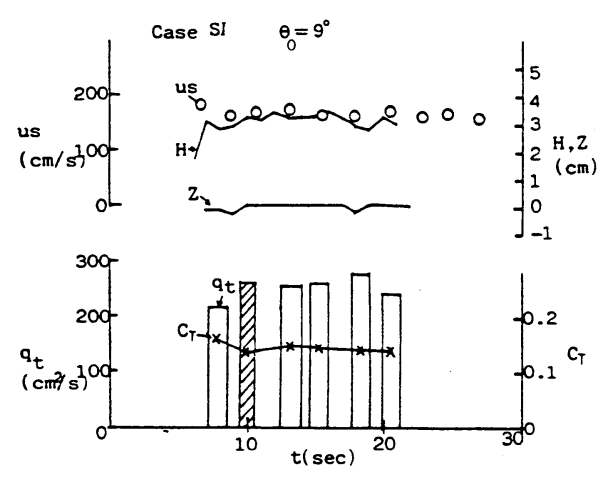

図-4 水理量の時間的変化

図-3 せん断層の無次元厚さと水路勾配の関係
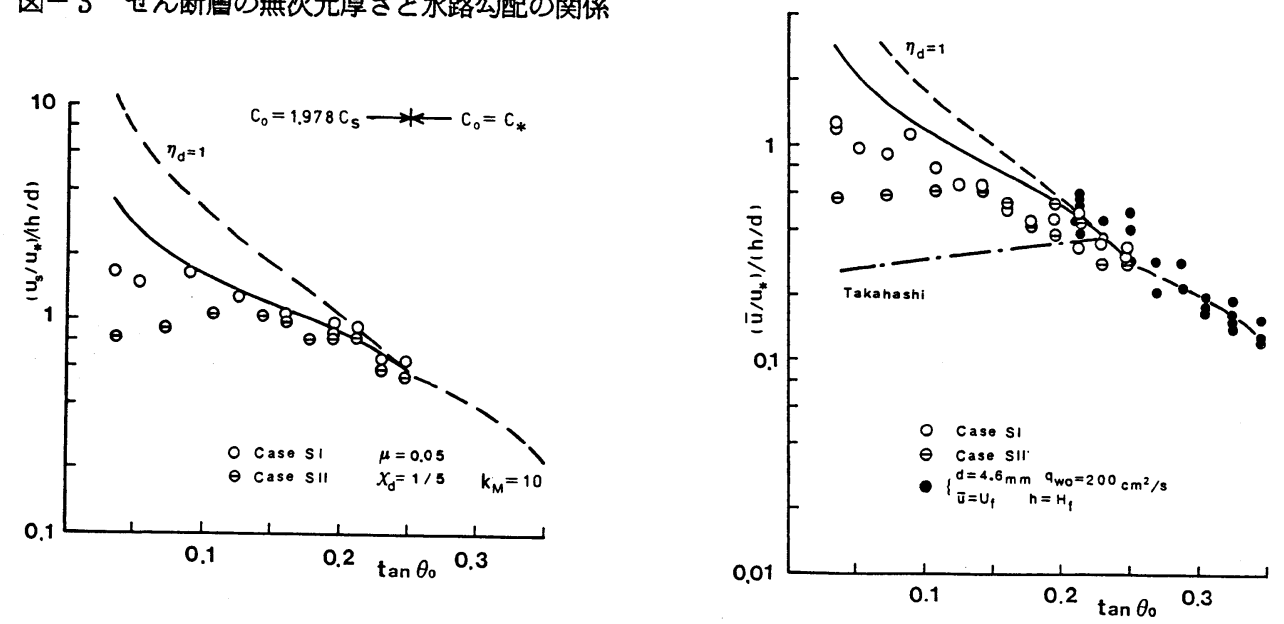

図- 5 表面流速の無次元表示と水路勾配の関係

四-6平均流速の無次元表示之水路勾配の関係 
の特徵である。このため, 水梁としては採用した時間内 で 40 個程度を読み取り平均したものを用いている。 図一 $5 ， 6$ は表面流速求よび平均流速 $\bar{u}=q_{t} / h$ の無 次元表示と水路勾配の関係をそれぞれ示したものである。 ここに, $u_{*}=\sqrt{\mathrm{gh \operatorname {sin } \theta}}$ 。摩擦速度である。なお 図一6には土石流勾配における実験結果も同時に示して いる。約 $8^{\circ}$ 以上の勾配では、無次元表面流速 $u_{s} /$ $u_{*}$ も流速係数 $\bar{u} / u_{*}$ もほほ $h / d$ に比例する之同時に、 勾配の增加に対しては明らかに減少している。これらは 土石流之同様な特性であり、高橋が示した理論 ${ }^{2)}$ とは 異なっている。また、四一7は砂碟の輸送濃度 $C_{T}$ およ びせん断層内における輸送濃度 $C_{d T}$ 之水路勾配の関係 を示している。ここに、一様流速部分の濃度を無視し， 便をせん断層の平均流速として， $C_{d T}$ は次式で与えられる。

$$
C_{d T}=C_{T}\left(\bar{u} / \overline{u_{d}}\right)\left(h / h_{d}\right)
$$

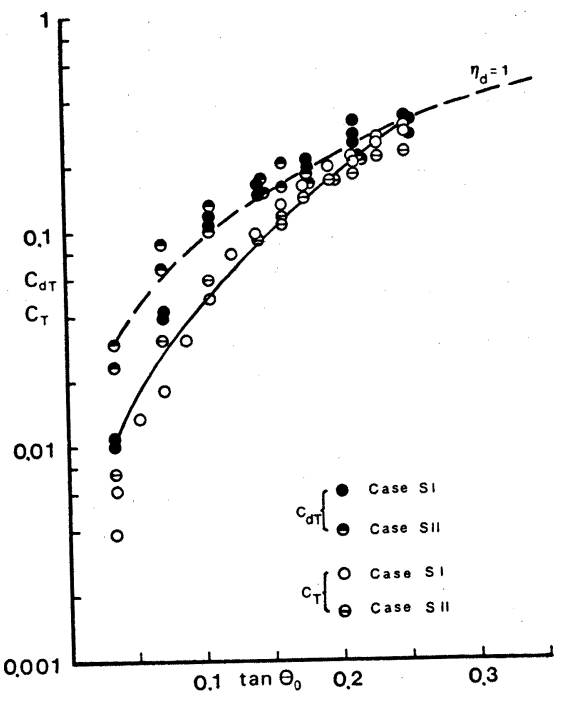

図-7 濃度と水路勾配の関係

$C_{T}$ には実験值を, $h / h_{d}, \bar{u} / \bar{u}_{d}$ には図-2の流速分 布の测定值から求めたものをそれぞれ用いて $C_{d T}$ を逆算 した。 $C_{d T}$ は一定ではなく，勾配と之もに増加している ことが分かる。

以上の結果, 水路㑯斜角 $\theta_{0}$ が約 $8^{\circ}$ 以上, せん断層 の相対厚さ $h_{d} / h$ は約 0.7 以上, 輸送濃度 $C_{T}$ は約，

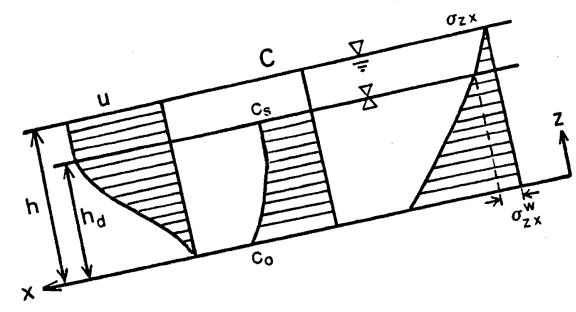

0.1以上のとき, 土石流に類似した抵抗特性を示すことが分かった。图ー8 2 層流モデル

4. 流動特性の解析

\section{（1） 2 層流モデル}

掃流状集合流動では，比較的高洤度の固・液せん断層の上に，港度が薄く，流速分布はほほ一様な水流層 が現われ，2 層流を呈している。そこで，一様流速の部分では濃度 C $=0$ とし，またせん断層では粒子相互 の接触により粒子間応力が発生し, 咲来の土石流における粒子間応力式が搪張して適用できるものとする (図一8)。したがって高濃度せん断層においては，土石流における取り扱いと同様に，流れ方向について 固·液両相の, 垂直方向については固相の力のつりあい式を立てると

$$
x:\{\sigma C+\rho(1-C)\} g \sin \theta_{0}+\frac{\partial \sigma_{z x}}{\partial z}=0 \quad \text { (1) } \quad z:-(\sigma-\rho) C g \cos \theta_{0}+\frac{\partial \sigma_{z z}}{\partial z}=0
$$

ここに， $\sigma_{z x}, \sigma_{z z}$ はそれぞれせん断応力, 垂直応力で, 粒子濃度をC, 最密充壃濃度を $C_{*}$ ， せん断層 表面濃度を $C_{s}$ ，水流のレイノルズ応力を $\sigma_{z x}^{w}$ ，粒子間応力に関する係数を $\alpha, K_{\mathrm{M}}, K_{\mathrm{p}}$ として

$$
\begin{aligned}
& \sigma_{z x}=K_{M} \sigma d^{2} \frac{\left(C / C_{*}\right)^{2}}{1-C / C_{*}}\left(\frac{\partial u}{\partial z}\right)^{2}+\sigma_{z x}^{w} \\
& \sigma_{z z}=-\frac{1}{\alpha} K_{M} \sigma d^{2} \frac{\left(C / C_{*}\right)^{2}}{1-C / C_{*}}\left(\frac{\partial u}{\partial z}\right)^{2}-K_{P} \frac{C}{C_{*}} \frac{C-C_{s}}{C_{s}}
\end{aligned}
$$


さらに, $\mu=0.05, \beta=1.15$ として

$$
\gamma=\frac{0.0762+0.102 \mu}{0.0898-0.067 \mu} \quad \alpha=\frac{\gamma}{1+\frac{\rho}{2 \sigma}} \quad K_{M}=\frac{\pi}{6}(0.0762+0.102 \mu) \beta^{2} k_{M}
$$

ここで $\sigma_{z x}^{w}$ の評価が問題となる。上部に水流層が存在しない土石流においては $\sigma_{z x}^{w}$ の寄与は粒子間応力に 比して微少だとし無視されている。粒子間応力式に伴う諸係数值は， $\sigma_{z x}^{w}$ を無視して求めた計算式が実験 結果に適合するように決定されたすのである。一方，掃流状集合流動の高濃度せん断層においては， $\sigma_{\boldsymbol{z} x}^{w}$ は上部水流層の存在のため必ずしも無視することはできないと考えられる。しかしながらその厥密な評価は 困難であり, 本論文では従来の土石流の式に接続されるため, $\sigma_{z x}^{w} \leftrightharpoons \rho g\left(h-h_{d}\right) \sin \theta_{0}$ としてせん断層内 では一定と仮定することにする。

以上の仮定と式 (1) 〜 (4) 功濃度勾配を規定する式として

$$
\frac{\partial C}{\partial \eta}=-\frac{\Psi C_{*}}{\chi_{d} \eta_{d}} \frac{C-C_{\alpha}}{2 C-C_{s}}
$$

を得る。ここに

$$
\Psi=\frac{\alpha-\tan \theta_{0}}{\alpha}
$$

$$
C_{\alpha}=\frac{\tan \theta_{0}}{\frac{(\sigma-\rho)}{\rho}\left(\alpha-\tan \theta_{0}\right)}
$$$$
\chi_{d}=\frac{K_{p}}{C_{S}(\sigma-\rho) g h_{d} \cos \theta_{0}}
$$

である。式（6）を $\eta=0$ で $C=C_{0}$ の境界条件で解くと

$$
\eta=\frac{\chi_{d} \eta_{d}}{\Psi C_{*}}\left\{2\left(C_{0}-C\right)-\left(2 C_{\alpha}-C_{s}\right) \ln \frac{C-C_{\alpha}}{C_{0}-C_{\alpha}}\right\}
$$

底面濃度 $C_{0}$ は移動床上の土石流では $C_{0}=C_{*}$ である。一方，掃流砂では $C_{0}<C_{*}$ と考えられる。両者の中間 的な流砂形態の掃流状集合流動においては，土石流之の限界勾配で土石流の境界条件に，掃流砂之の限界勾 配では掃流砂の境界条件に罝移する之考元られる。そのため $C_{0}=a_{0} C_{s}$ とおくことにする。ここにC $S C$ を 土石流之掃流状集合流動の限界勾配における表面濃度として $a_{0}=C_{*} / C_{S C}$ である。限界勾配を $\theta_{0}=14^{*}$ と すると $a_{0}=1.978$ となる。この境界条件では濃度分布は水路勾配の低下とともに一様化するようになる

(図一 2 の破線)。高濃度せん断層の表面濃度 は，式（7）で $\eta=\eta_{d} ， C=C_{s}$ とおいて変形すると

$$
\frac{C_{s}-C_{\alpha}}{C_{0}-C_{\alpha}}=\exp \left\{\frac{2\left(C_{0}-C_{\alpha}\right)-\frac{\Psi C_{*}}{\chi_{d}}}{2 C_{\alpha}-C_{s}}\right\}
$$

せん断層内の平均漶度は

$$
\overline{C_{d}}=C_{s}+\int_{C_{s}}^{C_{0}} \frac{\eta}{\eta_{d}} d C=C_{\alpha}+\frac{\chi_{d}}{\Psi C_{*}} C_{0}\left(C_{0}-C_{s}\right)
$$

高橋のモデルでの $\overline{C_{d}}$ は土石流発生限界勾配 $\theta_{0}=14^{\circ}$ における漶度を保持するが，本モデルの $\overline{C_{d}}$ は水路勾 配の低下とともに減少するのが特徵である。

速度分布については，まず式（6）を用いて式（1）を積分した後， $\sigma_{z x}$ に式（3）を代入すると，次 式

$$
\begin{aligned}
\frac{d}{d \eta} \frac{u}{u_{*}}=\frac{h}{d}\left(K_{M} \frac{\sigma}{\rho} \frac{\Psi C_{*}}{\chi_{d}}\right)^{-\frac{1}{2}} \eta d^{\frac{1}{2}} & \frac{\left(1-C / C_{*}\right)^{\frac{1}{2}}}{C / C_{*}}\left[\left(C-C_{s}\right)\left\{\frac{\sigma-\rho}{\rho}\left(C+2 C_{\alpha}\right)+2\right\}\right. \\
& \left.+\left(1+\frac{\sigma-\rho}{\rho} C_{\alpha}\right)\left(2 C_{\alpha}-C_{s}\right) \ln \frac{C-C_{\alpha}}{C_{s}-C_{\alpha}}\right]^{\frac{1}{2}}
\end{aligned}
$$


さらに式（6）を用いて上式を積分し，底面 $\eta=0$ で $C=C_{0}, u=0$ とおくと

$$
\begin{aligned}
& \frac{u}{u_{*}}=\frac{h}{d}\left\{K_{M} \frac{\sigma}{\rho}\left(\frac{\Psi C_{*}}{\chi_{d}}\right)^{3}\right\}^{-\frac{1}{2}} \eta_{d^{\frac{3}{2}} G(C)} \\
& \text { ここに } \quad F(C)=\frac{2 C-C_{s}}{C-C_{\alpha}} \frac{\left(1-C / C_{*}\right)^{\frac{1}{2}}}{C / C_{*}} {\left[\left(C-C_{s}\right)\left\{\frac{\sigma-\rho}{\rho}\left(C+2 C_{\alpha}\right)+2\right\}\right.} \\
&\left.+\left(1+\frac{\sigma-\rho}{\rho} C_{\alpha}\right)\left(2 C_{\alpha}-C_{s}\right) \ln \frac{C-C_{\alpha}}{C_{s}-C_{\alpha}}\right]^{\frac{1}{2}}
\end{aligned}
$$

として $G(C)=\int_{C}^{C_{0}} F(C) d C$

である。せん断層表面流速 $u_{s}$ は $C=C_{S}$ とおいて

$$
\frac{u_{s}}{u_{*}}=\frac{h}{d}\left\{K_{M} \frac{\sigma}{\rho}\left(\frac{\Psi C_{*}}{\chi_{d}}\right)^{3}\right\}^{-\frac{1}{2}} \eta_{d^{\frac{3}{2}} G\left(C_{s}\right)}
$$

無次元流速分布は

$$
u / u_{s}=G(C) / G\left(C_{s}\right)
$$

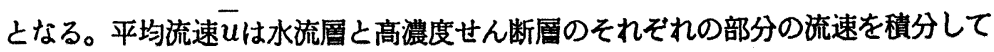

$$
\begin{aligned}
\frac{\bar{u}}{u_{*}} & =\int_{\eta_{d}}^{1} \frac{u}{u_{*}} d \eta+\int_{0}^{\eta_{d}} \frac{u}{u_{*}} d \eta \\
& =\left(1-\eta_{d}\right) \frac{k_{w} u_{s}}{u_{*}}+\frac{h}{d}\left\{K_{M} \frac{\sigma}{\rho}\left(\frac{\Psi C_{*}}{\chi_{d}}\right)^{5}\right\}^{-\frac{1}{2}} \eta_{d^{2}} G_{0}\left(C_{s}\right)
\end{aligned}
$$

ここに, $n=0$ と 1 の場合に対して次式が定義されている。

$$
G_{n}(C)=\int_{C}^{C_{0}} C^{n} \frac{2 C-C_{s}}{C-C_{\alpha}} G(C) d C
$$

また， $k_{w}$ は水流層の流速分布に関する補正係数で，水流層がほほ一様な分布を示すことから 式（14）に式（1 2) を代入して整理すると

$$
\frac{\bar{u}}{u_{*}}=\frac{h}{d}\left\{K_{M} \frac{\sigma}{\rho}\left(\frac{\Psi C_{*}}{\chi_{d}}\right)^{3}\right\}^{-\frac{1}{2}} \eta_{d^{\frac{3}{2}}}\left\{\left(1-\eta_{d}\right) k_{w} G\left(C_{s}\right)+\frac{\chi_{d} \eta_{d}}{\Psi C_{*}} G_{0}\left(C_{s}\right)\right\}
$$

最後に，輸送濃度 $C_{T}$ は高濃度せん断層内の水の流速を粒子速度に等しいとして次式で求められる。

$$
\begin{aligned}
C_{T} & =\int_{0}^{1} C u d \eta / \int_{0}^{1} u d \eta=\int_{0}^{\eta_{d}} C \frac{u}{u_{*}} d \eta / \frac{\bar{u}}{u_{*}} \\
& =\frac{\chi_{d} \eta_{d}}{\Psi C_{*}} G_{1}\left(C_{s}\right) /\left\{\left(1-\eta_{d}\right) k_{w} G\left(C_{s}\right)+\frac{\chi_{d} \eta_{d}}{\Psi C_{*}} G_{0}\left(C_{s}\right)\right\}
\end{aligned}
$$

以上の諸式において $\eta_{d}=1$ とおけば土石流の式と一致する。

(2)計算結果および実験との比較

まず, 式(8)において $C_{0}=1.978 C_{s}$ とおき各水路勾配毎に高濃度せん断層の表面濃度 $C_{s}$ を計算する。そ の結果，水路勾配の減少につれC $C_{s}$ は $C_{\alpha}$ に接近していき，約 $8^{\circ}$ 以下の勾配ではほほ $C_{s}=C_{\alpha}$ となる。同時 に濃度分布は底面付近を除いて一様化する。そのため表面付近で計算誤差が過大になったり，特異点が生し て計算不能に陥ったりする。このような難点をさけるため，数值積分のキザミ幅をできるだけ小さくして精 度をあげる一方で濃度分布に対して以下のような近似を行う。 


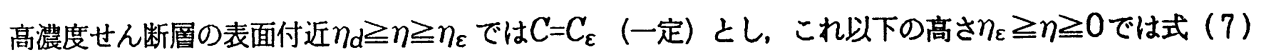
を用いて計算を行う。ここに, $\eta_{\varepsilon}$ は濃度が $C_{\varepsilon}=(1+\varepsilon) C_{s}$ となる高さで， $\varepsilon は \varepsilon=1.0 \times 10^{-4}$ 程度が妥当 である。

その結果，たとえば流速分布は式（11）において

$$
\begin{aligned}
0 \leqq \eta \leqq & \eta_{\varepsilon} \text { のとき } \\
G(C)= & \int_{C}^{C_{0}} \frac{2 C-C_{s}}{C-C_{\alpha}} \frac{\left(1-C / C_{*}\right)^{\frac{1}{2}}}{C / C_{*}}\left[\left(C-C_{\varepsilon}\right)\left\{2+\frac{\sigma-\rho}{\rho}\left(C+2 C_{\alpha}-C_{s}+C_{\varepsilon}\right)\right\}\right. \\
& \left.+\left(1+\frac{\sigma-\rho}{\rho} C_{\alpha}\right)\left(2 C_{\alpha}-C_{s}\right) \ln \left|\frac{C-C_{\alpha}}{C_{\varepsilon}-C_{\alpha}}\right|+\frac{\Psi C_{*}}{\chi_{d} \eta_{d}}\left(\frac{\sigma-\rho}{\rho} C_{\varepsilon}+1\right)\left(\eta_{d}-\eta_{\varepsilon}\right)\right]^{\frac{1}{2}} d C \\
\equiv & F_{d}(C) \\
\eta_{\varepsilon} \leqq \eta \leqq & \eta_{d} \text { のとき } \\
G(C)= & \frac{2}{3}\left(\frac{\Psi C_{*}}{\chi_{d} \eta_{d}}\right)^{\frac{3}{2}} \frac{C_{*}}{C_{\varepsilon}}\left\{\left(1-\frac{C_{\varepsilon}}{C_{*}}\right)\left(\frac{\sigma-\rho}{\rho} C_{\varepsilon}+1\right)\right\}^{\frac{1}{2}}\left\{\left(\eta_{d}-\eta_{\varepsilon}\right)^{\frac{3}{2}}-\left(\eta_{d}-\eta\right)^{\frac{3}{2}}\right\} \\
& +F_{d}\left(C_{\varepsilon}\right)
\end{aligned}
$$

と置き換えればよい。さらに，平均流速および輸送濃度も式（14），(16) の定䣡式から求めることが できる。

$\theta_{0} \leqq 9^{\circ}$ の水路勾配ではこのように近似して求められた式を， $\theta_{0} \geqq 9^{\circ}$ では式（7）〜（16）を用い

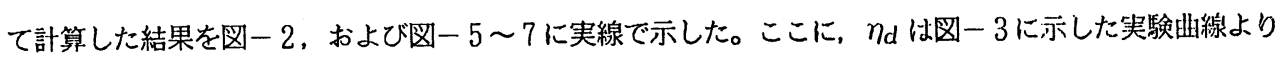
与えている。これらの図には比較のため $\eta_{d}=1$ の場合の計算結果も示している。 $\theta_{0}=9^{\circ}$ においては両者の 計算方法による值は一致している。また，表面流速および平均流速の無次元表示の計算では，土石流限界勾 配の $\theta_{0}=14^{\circ}$ において実駼結果に適合させるため, 衝突における運動量伝達に関する係数を $k_{M}=10$ とお いている。 $\theta_{0} \geqq 8^{\circ}$ では，実験と理論は概ね一致していることが分る。

\section{5. 結語}

以上，掃流状集合流動に対して 2 層流モデルを考え，濃度，流速分布，平均流速および輸送濃度などの計 算式を提示した。その結果, $\theta_{0} \geqq 8^{\circ}$ で岋計算式が実験結果をかなり良く説明することを示した。しかし ながら，本モデルでのレイノルズ応力の考察にはなお検討の余地があり，またせん断層の相対厚さ的 を実 験結果より評価しているなど細部については多くの問題が残されている。今後はこれらについてさらに検討 を加えていく予定である。

最後に, 実験, データ整理において元野一生（現・運輸省）および本学院生の榎村康史の両氏に多大の助 力を受けた。記して感謝の意を表します。

\section{参考文献}

1). 水山高久：土石流から掃流に変化する勾配での流砂量, 新砂防, 116 号, 1980 .

2）高橋 保: 土石流の停止, 堆積機構に関する研究(3)一土石流扇状地の 2 次侵食一, 京都大学防災 研究所年報, 25 号B-2, 1982 .

3）椿東一郎, 橋本晴行, 末次忠司: 土石流における粒子間応力之流動特性, 土木学会論文報告集, 第 317 号, 1982 . 